\title{
Tumor Replication Error Analysis
}

National Cancer Institute

\section{Source}

National Cancer Institute. Tumor Replication Error Analysis. NCI Thesaurus. Code C18307.

Certain tumors contain widespread deletions within mono- and dinucleotide repeat sequences in their DNA, referred to as the replication error (RER+) phenotype. The RER+ status of tumors is usually determined by examining several dinucleotide and mononucleotide repeats for size variations when compared with the matching normal DNA. 